\title{
Early infection and asymptomatic spread of hepatitis A virus in a public child care center in Rio de Janeiro, Brazil: Should attending children under two years of age be vaccinated?
}

\author{
Liliane M Morais/ ${ }^{+}$, Vanessa S de Paula, Milton R Arantes*, Maria LA O liveira, \\ Ana Maria C Gaspar
}

\author{
Departamento de Virologia, Instituto Oswaldo Cruz-Fiocruz, Av. Brasil 4365, 21045-900 Rio de Janeiro, RJ, Brasil \\ *Hospital Geral da Santa Casa de Misericórdia, Rio de Janeiro, RJ, Brasil
}

\begin{abstract}
A cross-sectional study was conducted in order to identify hepatitis A virus (HAV) serological markers in 418 individuals (mean age, 16.4 years; range, 1 month-80 years) at a public child care center in Rio de Janeiro, Brazil, as well as to analyze risk factors and determine circulating genotypes. Serum samples were tested using an enzyme immunoassay. Reverse transcription polymerase chain reaction (RT-PCR) was used to detect and characterize HAV RNA, and sequencing was performed. Anti-HAV antibodies and IgM anti-HAV antibodies were detected, respectively, in $89.5 \%$ (374/418) and $10.5 \%$ (44/418) of the individuals tested. Acute HAV infection in children was independently correlated with crawling ( $p<0.05)$. In 56.8\% (25/44) of the IgM anti-HAV-positive individuals and in $33.3 \%$ (5/15) of the IgM anti-HAV-negative individuals presenting clinical symptoms, HAV RNA was detected. Phylogenetic analysis revealed co-circulation of subgenotypes IA and IB in 93.3\% (28/30) of the amplified samples. In present study, we verify that 79\% (30/38) of children IgM anti-HAV-positive were asymptomatic. In child care centers, this asymptomatic spread is a more serious problem, promoting the infection of young children, who rarely show signs of infection. Therefore, vaccinating children below the age of two might prevent the asymptomatic spread of hepatitis A.
\end{abstract}

Key words: hepatitis A antibodies - hepatitis A virus subgenotypes IA and IB - hepatitis A - risk factors - Brazil

Hepatitis A virus (HAV) is a hepatotropic virus and a member of the Hepatovirus genus within the Picornaviridae family (Minor 1991). The virus is responsible for the majority of the acute hepatitis cases in Brazil (Gaspar et al. 1996), and infection symptoms are age-related. Among HAV-infected individuals, children under 6 years old are typically asymptomatic, whereas older children and adults develop jaundice or present dark urine. The prevalence of HAV infection is closely correlated with the level of environmental sanitation and with prevailing socioeconomic and hygiene conditions. The incidence of HAV is higher in developing countries, although the pattern of HAV endemicity in several of these countries has dropped from high to intermediary due to improvements in sanitation conditions in recent decades (Tapia-Conyer et al. 1999, Tanaka 2000). As a consequence, increasing proportions of those populations have had no contact with HAV and are therefore more susceptible to infection. In Brazil, hepatitis A is still considered an endemic disease, although data collected in the state of Rio de Janeiro indicate that a shift in the hepatitis A epidemiological pattern has taken place (Santos et al. 2002, Villar et al. 2002).

The virus is usually transmitted via the fecal-oral route, either through person-to-person contact or through in-

Financial support: $\mathrm{CNPq}$

${ }^{+}$Corresponding author: moraislm@ioc.fiocruz.br

Received 31 January 2006

Accepted 5 May 2006 gestion of contaminated food or water. On rare occasions, HAV infection has been transmitted by transfusion of contaminated blood or blood products (Pereira \& Gonçalves 2003). Outbreaks in day care centers have been related since the 1970s (Gehlbach et al. 1973, Williams et al. 1975). Results of some studies have suggested that HAV is transmitted mainly by children with either asymptomatic or subclinical infection. Lack of proper hygiene facilitates HAV transmission from such children to their relatives and friends, as well as to child care center staff members (Castelli et al. 1999, Poovorawan et al. 2005).

The HAV strains have been classified into six genotypes (I to VI), based on nucleotide sequences of the VP1/2A junction region (Robertson et al. 1992, Lu et al. 2004). Prevalent human strains fall into genotypes I or III, each of which are divided into subtypes A and B. In Brazil, co-circulation of subgenotypes IA and IB have been found in Rio de Janeiro (de Paula et al. 2002, Villar et al. 2004). Circulation of subgenotype IA has also been detected in other regions of Brazil (de Paula et al. 2004).

Since it was first reported that HAV was able to propagate in cell culture (Provost et al. 1979), there have been many attempts to develop an HAV vaccine. In the United States and some other countries, safe and effective formalin-inactivated HAV vaccines against hepatitis A have been licensed and are available for children aged 2 years and older (CDC 1999). In Brazil, no HAV vaccine has been included in public health programs.

Herein, we report the asymptomatic spread of HAV occurring in a public child care center in Brazil. Most individuals in the center were younger than 10 years of age. 


\section{MATERIALS AND METHODS}

Study population - In a cross sectional study conducted in October 1999, serum samples were collected from 418 individuals ( 261 children and 157 staff members) at a child care center located in an urban area of Rio de Janeiro, Brazil. Of the total, $54.3 \%$ were female, and $45.7 \%$ were male. Ages ranged from 1 month to 80 years (mean, 16.4 years; median, 5 years). A questionnaire was applied in order to assess employment status and to evaluate potential risk factors for infection. All samples were collected on a single day, after which they were immediately frozen and stored at $-20^{\circ} \mathrm{C}$ until processing. Written informed consent was obtained from adult participants and from the parents or legal guardians of participating children. The present study was approved by the Ethics Committee of the Oswaldo Cruz Foundation (Fiocruz), operating under the auspices of the Brazilian Health Ministry.

Background - The center evaluated functions both as an orphanage and as a child care center for the children with families. However, the children were not segregated based on this status, being allocated to classrooms based solely on age and gender. In June 1999, the first case of hepatitis A at this child care center was reported. The infected child was two-and-a-half years old and lived in an area of Rio de Janeiro that has poor sanitary conditions. Three months later, a staff member presented clinical symptoms of hepatitis. The Brazilian Reference Center for Viral Hepatitis, Fiocruz, was called in to investigate the immunity level of this population.

The child care center was housed in a 3-story building with a kitchen, cafeteria, yard and nursery, as well as 20 additional rooms, including a study, dorms and recreational classrooms. On each floor, there were five bathrooms and four drinking fountains. The same cooks prepared the meals for everyone in the center. There was only one cafeteria and meals were served to children of same age group at a time.

Laboratory tests - Serum specimens were tested for IgM anti-HAV and total anti-HAV antibodies using a commercial enzyme immunoassay (Organon Teknika, Boxtel, The Netherlands), according to manufacturer instructions.

Statistical analysis - Data are expressed as mean \pm standard deviation. Differences in the prevalence of antiHAV among different age groups were analyzed using the chi-square test. A linear regression model was applied to test for a linear association between age and the prevalence of anti-HAV. A multiple logistic regression model was applied to investigate which independent variables significantly on the prevalence of IgM anti-HAV. A twotailed $\mathrm{p}<0.05$ was considered statistically significant. The statistical analysis was performed using the Statistical Package for the Social Sciences (SPSS for IBM-PC, release 11.0; SPSS Inc., Chicago, IL, US).

Molecular tests - The VP1/2A junction region of the HAV genome was amplified using reverse transcription polymerase chain reaction (RT-PCR) followed by a second round of PCR. Nucleotide sequencing from extracted HAV RNA was carried out as described elsewhere (de Paula et al. 2002).
Phylogenetic analysis - Nucleotide sequences were aligned using the GCG Wisconsin Package (Wisconsin Genetics Group, Madison, WI, US). Initial multiple alignments were performed using the PILEUP program (Wisconsin Genetics Group). Further adjustments were performed manually using visual correction based on sequence comparison generated with the PRETTY program included in the GCG Wisconsin Package (Wisconsin Genetics Group). The MEGA 2.1 program (The Biodesign Institute, Tempe, AZ, US) was used to calculate nucleotide identities and genetic distances between sequences, as well as to construct a phylogenetic tree. The phylogenetic tree was constructed using the neighbor-joining method.

\section{RESULTS}

Laboratory analysis - The overall rate of positivity for total anti-HAV was $89.5 \%$. IgM anti-HAV antibodies were detected in $44(10.5 \%)$ of the 418 individuals tested: 6 staff members and 38 children. Among the 38 children testing positive for IgM anti-HAV, 30 (79\%) were asymptomatic. Table I shows the age-specific prevalence of antiHAV antibodies (total and IgM) in the studied population. The total anti-HAV prevalence was more than $60 \%$ in all age groups. We observed that the prevalence of $\operatorname{IgM}$ anti-HAV decreased in parallel with increasing age. In subjects between 7 months and 1 year of age, the prevalence was $26.7 \%$, compared with $1.1 \%$ in those older than 30 . After detection of anti-HAV antibodies, all susceptible subjects aged 2 years or older $(n=43)$ were immunized with an inactivated hepatitis A vaccine (Havrix ${ }^{\circledR}$, manufactured by SmithKline Beecham Biologicals, Rixensart, Belgium).

Risk factors - Risk factors were investigated only in children $(\mathrm{n}=261)$ because there were few adults testing positive for IgM anti-HAV. In this study, we considered the following as risk factors: fingernail biting, pacifier use and crawling. Initially, HAV infection was found to correlate significantly with pacifier use $(\mathrm{p}=0.023)$ and with crawling ( $\mathrm{p}=0.002)$ (Table II). However, after logistic regression, crawling was identified as the only independent risk factor (OR: 4.8; 95\% CI: 1.1-19.6) for acute HAV infection.

Molecular analysis - To investigate HAV dissemination, RT-PCR was used to test for HAV RNA in all 44 serum samples collected from IgM anti-HAV positive individuals. Sera from 15 individuals who were negative for IgM anti-HAV but presented jaundice or dark urine were also tested. We detected HAV RNA in $25(56.8 \%)$ of the 44 samples from IgM anti-HAV-positive individuals and in 5 (33.3\%) of the 15 samples from individuals who presented clinical symptoms only. A 168-bp nucleotide sequence of the VP1/2A region of the HAV genome was identified in 28 (93.3\%) of the 30 amplified samples. Of those 28 samples, 17 were of subgenotype IA and 11 were of subgenotype IB (Figure). Sequences reported in this paper have been deposited in the GenBank database under the accession numbers DQ061160 to DQ061187. 
TABLE I

Prevalence of anti-hepatitis A virus (HAV) antibodies (total and $\operatorname{IgM}$ ) in the population of a Brazilian child care center, by age group

\begin{tabular}{|c|c|c|c|c|c|}
\hline \multirow[b]{2}{*}{ Age group } & \multirow[b]{2}{*}{$\mathrm{n}$} & \multicolumn{2}{|c|}{ Anti-HAV } & \multicolumn{2}{|c|}{ IgM anti-HAV } \\
\hline & & Positive & $\%$ & Positive & $\%$ \\
\hline $1-6^{a}$ & 7 & 5 & 71.4 & 0 & 0 \\
\hline $7^{a}-1^{b}$ & 30 & 18 & 60 & 8 & 26.7 \\
\hline $2-3^{b}$ & 79 & 69 & 87.3 & 9 & 11.4 \\
\hline $4-5^{b}$ & 94 & 83 & 88.3 & 18 & 19.1 \\
\hline $6-10^{b}$ & 41 & 38 & 92.7 & 3 & 7.3 \\
\hline $11-15^{b}$ & 23 & 23 & 100 & 2 & 8.7 \\
\hline $16-20^{b}$ & 15 & 15 & 100 & 1 & 6.7 \\
\hline $21-25^{b}$ & 15 & 112 & 80 & 1 & 6.7 \\
\hline $26-30^{b}$ & 24 & 23 & 95.8 & 1 & 4.2 \\
\hline$>30^{b}$ & 90 & 8 & 97.8 & 1 & 1.1 \\
\hline Total & 418 & 374 & 89.5 & 44 & 10.5 \\
\hline
\end{tabular}

$a$ : month; $b$ : year

TABLE II

Risk factors associated with hepatitis A virus (HAV) infection in children at the child care center

\begin{tabular}{lcccc}
\hline & \multicolumn{2}{c}{ IgM anti-HAV } & & \\
\cline { 2 - 3 } Risk factor & Pos $(\%)$ & Neg $(\%)$ & Odds Ratio (95\% CI) & p value \\
\hline Fingernail biting & 7.1 & 2.3 & $3.2(03-33.6)$ & 0.299 \\
Pacifier use & 52.9 & 32.9 & $2.3(1.1-4.8)$ & 0.023 \\
Crawling & 14.3 & 2.3 & $7.0(1.9-25.6)$ & 0.002 \\
\hline
\end{tabular}

\section{DISCUSSION}

The laboratory tests conducted in the present study were performed in October 1999 and thus four months after the first case had been reported. Of the 418 individuals (261 children and 157 members) tested at that time, 374 $(89.5 \%)$ presented anti-HAV antibodies and $44(10.5 \%)$ were IgM anti-HAV positive. Among the $38 \mathrm{IgM}$ anti-HAVpositive children, 30 (79\%) were asymptomatic. The asymptomatic status of those children may have facilitated the transmission of HAV. It is well known that children under 6 years of age rarely show clinical signs of HAV infection. Poovorawan et al. (2005) studied an outbreak that occurred in a child care center in Thailand and found that 65 of the 70 children testing positive for $\operatorname{IgM}$ antiHAV were asymptomatic. Since HAV infection can be disseminated by asymptomatic individuals, and the majority of HAV infections in young children are of the 'silent' type, the findings of those authors, taken together with those of the present study, indicate that hepatitis A represents a great threat in child care centers.

Of the potential risk factors analyzed, crawling proved to be an independent factor, correlating significantly with acute HAV infection ( $p=0.002$, after adjustment by multivariate analysis). These data suggest that children under 2 years of age promote HAV infection when they start crawling since HAV infection naturally occurs through direct hand-to-mouth contact, mainly in endemic countries where there is widespread HAV dissemination in the environment. In addition, children that crawl typically wear diapers that need to be changed regularly. Inadequate diaper-changing facilities may also contribute to HAV transmission. Indeed, previous findings indicate that the presence of young children wearing diapers is a factor that facilitates the spread of HAV in child care centers (Rosenblum et al. 1991, Venczel et al. 2001).

Using molecular analysis, we detected the co-circulation of subgenotypes IA and IB, which corroborates the findings of other studies conducted in Rio de Janeiro (de Paula et al. 2002, Villar et al. 2004). The co-circulation of two subgenotypes suggests the existence of more than one source of infection. The occurrence of simultaneous community outbreaks is also a possibility.

We detected two potential sources of hepatitis A transmission in the child care center. The first source was a cook (staff member \#092) who had HAV acute infection. Nucleotide sequencing of a sample collected from that staff member revealed that the HAV genotype (subgenotype IA) was identical to that observed in the other 13 strains isolated in samples collected from individuals in the various classrooms, suggesting that this handler-food can have been a source of transmission (Figure). Previous studies have shown that HAV-excreting food handlers can contaminate the food they handle (Bidawid et al. 2000, Fiore 2004). The second potential source of HAV infection is the children infected with subgenotypes IA and IB who attend the child care center but live in areas with poor sanitary conditions. These children might have contracted the illness outside the 


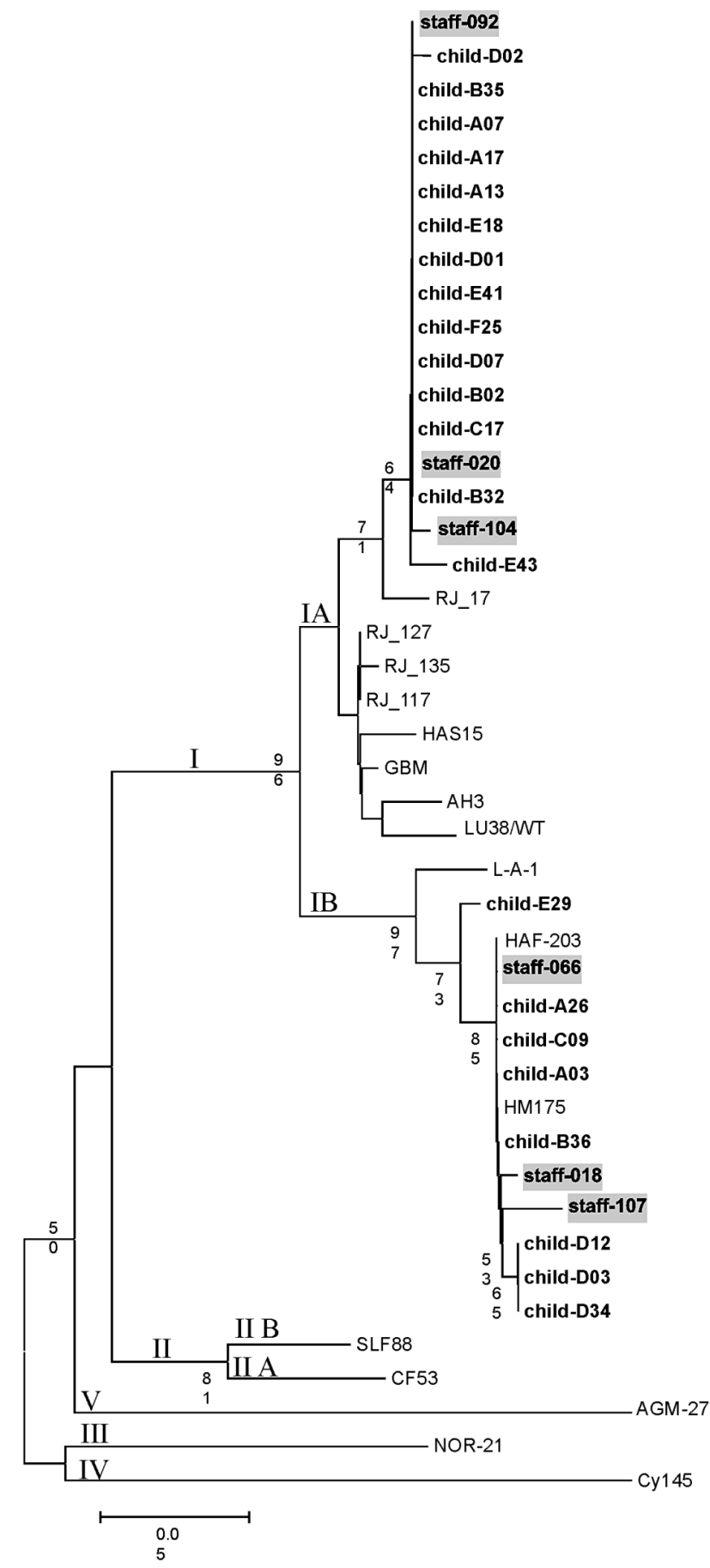

Phylogenetic tree based on a 168-bp sequence of the VP1/2A region and depicting the genetic relatedness between isolates found in this study (in bold) and other HAV strains previously characterized. Letters A, B, C, D, E, and F indicate classrooms. Isolates from staff members are in bold and shaded grey. Numbers located at nodes indicate bootstrap percentages after 1000 replicate samplings. Only percentages $\geq 50 \%$ are shown. Genbank sequences used as references included strains of subgenotype IA (accession numbers AY322886, AY322856, AY322901, AY322855, X15464, X75214, AB020566, and AF357222), subgenotype IB (accession numbers AF314208, AF268396, and M14707), subgenotype IIA (accession number AY644676), subgenotype IIB (accession number AY644670), subgenotype III (accession number AJ299464), subgenotype IV (accession number L07732) and subgenotype V (accession number D00924). The horizontal scale bar at the bottom of the tree is used to determine genetic distance. center and then transmitted it to others inside. In addition, infected staff members (subgenotypes IA and IB) had open access to all classrooms and might or might not have complied with hygiene regulations, which could have facilitated HAV dissemination.

The high prevalence of total anti-HAV $(71.4 \%)$ in children under 7 months of age who tested negative for IgM anti-HAV strongly suggests passive acquisition of maternal antibodies. However, previous studies have shown that, after 7 months of age, maternal antibodies diminish rapidly, favoring the occurrence of early infection (Vitral et al. 1998, Linder et al. 1999). In our study, $26.7 \%$ of the children aged 7 months to 1 year had already had acute HAV infection. These findings suggest that children attending child care centers in endemic countries such as Brazil should be vaccinated before the age of two. A study conducted in India presented data suggesting that children should be immunized against HAV by 10 months of age, when the maternal antibodies disappear (Chadha et al. 1999). Pre-existing maternal antibodies do interfere with the immune response to hepatitis A vaccine (Dagan et al. 2000, Letson et al. 2004), although some studies have shown that infants born to anti-HAV-positive mothers develop anamnestic responses with a booster dose of hepatitis A vaccine (Fiore et al. 2003, Letson et al. 2004).

Our data suggest that, should vaccination against $\mathrm{HAV}$ become a routine practice in endemic countries such as Brazil, children under 2 years of age should be the main target of vaccination campaign efforts, particularly before they begin attending child care centers.

\section{ACKNOWLEDGMENTS}

To the staff of the child care center, especially Sister Maria Rita, for their help, to the staff from the Brazilian Reference Center for Viral Hepatitis for their help and support with sample collection and to Dr Christian Niel for reviewing the manuscript.

\section{REFERENCES}

Bidawid S, Farber JM, Sattar SA 2000. Contamination of foods by food handlers: experiments on hepatitis A virus transfer to food and its interruption. Appl Environ Microbiol 66: 2759-2763.

Castelli F, Matteelli A, Signorini L, Scalvini C, Romano L, Tanzi E, Brunori A, Cadeo GP, Zanetti AR 1999. Pediatric migration and hepatitis A risk in host population. J Travel Med 6: 204-206.

Centers for Disease Control and Prevention 1999. Prevention of hepatitis A through active or passive immunization: recommendations of the Advisory Committee on Immunization Practices (ACIP). MMWR 48: RR-12.

Chadha MS, Chitambar SD, Shaikh NJ, Arankalle VA 1999. Exposure of Indian children to hepatitis A virus \& vaccination age. Indian J Med Res 109: 11-15.

Dagan R, Amir J, Mijalovsky A, Kalmanovitch I, Bar-Yochai A, Thoelen S, Safary A, Ashkenazi S 2000. Immunization against hepatitis $\mathrm{A}$ in the first year of life: priming despite the presence of maternal antibody. Pediatr Infect Dis J 19: 10451052.

de Paula VS, Baptista ML, Lampe E, Niel C, Gaspar AMC 2002. Characterization of hepatitis A virus isolates from 
subgenotypes IA and IB in Rio de Janeiro, Brazil. J Med Virol 66: 22-27.

de Paula VS, Lu L, Niel C, Gaspar AM, Robertson BH 2004. Genetic analysis of hepatitis A virus isolates from Brazil. J Med Virol 73: 378-383.

Fiore A E 2004. Hepatitis A transmitted by food. Clin Infect Dis 38: 705-715.

Fiore AE, Shapiro CN, Sabin K, Labonte K, Darling K, Culver D, Bell BP, Margolis HS 2003. Hepatitis A vaccination of infants: effect of maternal antibody status on antibody persistence and response to a booster dose. Pediatr Infect Dis J 22: 354-359.

Gaspar AMC, Oliveira JM, Silva MLP, Yoshida CFT 1996. Orally transmitted acute hepatitis in Rio de Janeiro, Brazil (1989-1995). In Y Buisson, P Coursaget, M Kane (eds), Enterically-transmitted Hepatitis Viruses, La Simarre, Jouèlès-Tours, France, p. 99-100.

Gehlbach SH, MacCormack JN, Drake BM, Thompson WV 1973. Spread of disease by fecal-oral route in day nurseries. Health Serv Rep 88: 320-322.

Letson GW, Shapiro CN, Kuehn D, Gardea C, Welty TK, Krause DS, Lambert SB, Margolis HS 2004. Effect of maternal antibody on immunogenicity of hepatitis A vaccine in infants. J Pediatr 144: 327-332.

Linder N, Karetnyi Y, Gidony Y, Dagan R, Ohel G, Levin E, Mendelson E, Barzilai A 1999. Decline of hepatitis A antibodies during the first 7 months of life in full-term and preterm infants. Infection 27: 128-131.

Lu L, Ching KZ, de Paula VS, Nakano T, Siegl G, Weitz M, Robertson BH 2004. Characterization of the complete genomic sequence of genotype II hepatitis A virus (CF53/ Berne isolate). J Gen Virol 85: 2943-2952.

Minor P 1991. Picornaviridae. In RIB Francki , CM Fauquet, DL Knudson, F Brown (eds), Classification and Nomenclature of Viruses, Springer-Verlag, Wien, p. 320-326.

Pereira FE, Gonçalves CS 2003. Hepatitis A. Rev Soc Bras Med Trop 36: 387-400.

Poovorawan Y, Theamboonlers A, Chongsrisawat V, Jantaradsamee P, Chutsirimongkol S, Tangkijvanich P 2005. Clinical features and molecular characterization of hepatitis A virus outbreak in a childcare center in Thailand. J Clin Virol 32: 24-28.
Provost, P. J., and M. R. Hilleman 1979. Propagation of human hepatitis A virus in cell culture in vitro. Proc Soc Exp Biol Med 160: 213-221.

Robertson BH, Jansen RW, Khanna B, Totsuka A, Nainan OV, Siegl G, Widell A, Margolis HS, Isomura S, Ito K, Ishisu T, Moritsugu Y, Lemon SM 1992. Genetic relatedness of hepatitis A virus strains recovered from different geographical regions. J Gen Virol 73: 1365-1377.

Rosenblum LS, Villarino ME, Nainan OV, Melish ME, Hadler SC, Pinsky PP, Jarvis WR, Ott CE, Margolis HS 1991. Hepatitis A outbreak in a neonatal intensive care unit: risk factors for transmission and evidence of prolonged fecal excretion among preterm infants. J Infect Dis 164: 476-482.

Santos DC, Souto FJ, Santos DR, Vitral CL, Gaspar AM 2002. Seroepidemiological markers of enterically transmitted viral hepatitis $\mathrm{A}$ and $\mathrm{E}$ in individuals living in a community located in the North Area of Rio de Janeiro, RJ, Brazil. Mem Inst Oswaldo Cruz 97: 637-640.

Tanaka J 2000. Hepatitis A shifting epidemiological in Latin America. Vaccine 18: S57-S60.

Tapia-Conyer R, Santos JI, Cavalcanti AM, Urdaneta E, Rivera L, Manterola A, Potin M, Ruttiman R, Tanaka Kido J 1999. Hepatitis A in Latin America: a changing epidemiologic pattern, Am J Trop Med Hyg 61: 825-829.

Venczel LV, Desai MM, Vertz PD, England B, Hutin YJ, Shapiro $\mathrm{CN}$, Bell BP 2001. The role of childcare in a communitywide outbreak of hepatitis A. Pediatrics 108: E78.

Villar LM, da Costa MCE, de Paula VS, Gaspar AMC 2002. Hepatitis A outbreak in a public school in Rio de Janeiro, Brazil. Mem Inst Oswaldo Cruz 97: 301-305.

Villar LM, Lampe E, Meyer A, Gaspar AM 2004. Genetic variability of hepatitis A virus isolates in Rio de Janeiro: implications for the vaccination of school children. Braz J Med Biol Res 37: 1779-1787.

Vitral CL, Yoshida CFT, Lemos ERS, Teixeira CS, Gaspar AMC 1998. Age-specific prevalence of antibodies to hepatitis A in children and adolescents from Rio de Janeiro, Brazil, 1978 and 1995. Relationship of prevalence to environmental factors. Mem Ins Oswaldo Cruz 93: 1-5.

Williams SV, Huff JC, Bryan JA 1975. Hepatitis A and facilities for preschool children. J Infect Dis 131: 491-495. 
